\title{
Design Thinking como ferramenta de Inclusão Social e diferencial competitivo nas Associações Agrícolas no Cariri Cearense.
}

Design Thinking as a tool for Social Inclusion and competitive differential in the Agricultural Associations in Cariri Cearense.

CASTEIÃO, André Luiz; Mestre; Universidade Federal do Cariri

andre.casteiao@ufca.edu.br

XENOFONTE, Felipe; Graduando; Universidade Federal do Cariri

felipeflx@hotmail.com

MELO, Magdala; Graduando; Universidade Federal do Cariri

magdala.psi@gmail.com

\section{Resumo}

Este trabalho tem como objetivo relatar a experiência dos alunos do Programa de Educação Tutorial (PET), do Curso de Design de Produto da Universidade Federal do Cariri, em parceria com o Instituto Agropólos/CE e a Enactus, no desenvolvimento de uma marca para os associados do Sítio Boa Esperança, produtores de óleo de Babaçu e Macaúba. Primeiramente, expõem-se o referencial teórico e os métodos adotados. O Design Thinking como método de inclusão social e as teorias de Papanek e Margolin afirmam que a melhoria de vida não se traduz apenas com o incremento da renda, mas também por meio da incorporação de valores socioambientais que promovam o desenvolvimento sustentável das comunidades que participaram deste projeto. Os resultados finais demonstraram que as metodologias do Design Thinking possibilitaram a Inclusão Social por meio da integração da população no desenvolvimento de produtos sustentáveis.

Palavras Chave: design thinking; inclusão social; co-criação; educação tutorial.

\section{Abstract}

This work aims to report on the experience of the students of the Tutorial Education Program (PET), the Product Design Course of the Federal University of Cariri, in partnership with Instituto Agropolos /CE and Enactus, in the development of a brand for the associated of Sitio Boa Esperança, producers of Babaçu and Macaúba oil. Firstly, the theoretical framework and the adopted methods are exposed. Design Thinking as a method of social inclusion and the theories of Papanek and Margolin affirm that the improvement of life is not only reflected in the increase of income, but also through the incorporation of socio-environmental values that promote the sustainable development of the communities that participated in this project. The final results demonstrated that the methodologies of Design Thinking made possible the Social Inclusion through the integration of the population in the development of sustainable products.

Keywords: design thinking; social inclusion; co- creation; tutorial education. 


\section{Introdução}

Num contexto atual, onde o regionalismo, o desenvolvimento social e a sustentabilidade tornam-se cada vez mais importantes, o design assume um papel estratégico de inserir nas comunidades locais a possibilidade de desenvolvimento e o aumento da competitividade por meio de seus métodos e soluções inovadoras.

O objetivo deste trabalho é relatar a experiência dos alunos do Programa de Educação Tutorial (PET), do Curso de Design de Produto da Universidade Federal do Cariri, em parceria com o Instituto Agropólos/CE e a Enactus', no desenvolvimento de uma marca para os associados do Sitio Boa Esperança, produtores de óleo de Babaçu e Macaúba, promovendo por meio desta união o desenvolvimento regional, a inclusão social e o incentivo a atividades empreendedoras.

Os desafios atuais de formar jovens designers demandam dos cursos de graduação em Design o enfoque regional e cultural para estimular o pensamento crítico e a capacidade de propor e implementar estratégias inovadoras. O desenvolvimento de projetos regionais promove nos estudantes a prática projetual e a visualização dos resultados nas suas próprias comunidades e ou regiões.

Para Oliva (2003), o termo regionalidade é utilizado para qualificar as ações que resultam do esforço conjunto de todas as áreas produtivas que visam destacar, desenvolver e difundir as habilidades e características de uma região, procurando torná-la um centro de referência. 0 desenvolvimento pode ser entendido como um processo de potencialização das oportunidades e características existentes em cada território. Diante das diferenças geográficas, econômicas, sociais e culturais, em especial a aquelas referentes à atividade do Design, percebe-se, atualmente uma grande participação de profissionais comprometidos com suas regiões, contribuindo na formulação de políticas que visem destacar e valorizar produção e produto, contemplando influências culturais e especificidades da região em seus projetos.

Neste trabalho, primeiramente, expõem-se o referencial teórico e os métodos adotados. A seguir, descreve-se a iniciativa e os resultados obtidos e apresentam-se as considerações finais do trabalho, com o propósito de contribuir para o avanço na reflexão sobre o tema e para a proposição de caminhos e ideias para a compreensão da questão a partir de pesquisa, análises e experimentação conduzidas e orientadas pelo Design.

\section{Sustentabilidade, Regionalismo e Inclusão social}

\subsection{Desenvolvimento Sustentável}

O conceito de desenvolvimento sustentável, um dos temas deste projeto, foi introduzido no debate internacional pelo documento da World Commission for Environment and Development Our Common Future. De acordo com a WCED (1987), Sustentabilidade Ambiental refere-se às condições sistêmicas segundo as quais, em nível regional e planetário, as atividades humanas não devem interferir nos ciclos naturais em que se baseia tudo o que a resiliência do planeta permite e, ao mesmo tempo, não devem empobrecer seu capital natural, que será transmitido às gerações futuras.

${ }^{1}$ Enactus é uma organização internacional sem fins lucrativos que trabalha com líderes empresariais e de ensino 
superior para mobilizar universitários a fazer a diferença em suas comunidades. A Enactus UFCA iniciou em 2009, com o objetivo de explorar as potencialidades da Região do Cariri, transformando as comunidades através de projetos sociais que promovam a melhoria da qualidade de vida dos envolvidos.

Segundo Margolin (2003) o objetivo primário do design para o mercado é criar produtos para a venda. De modo contrário, o objetivo primordial do design social é a satisfação das necessidades humanas. Contudo, neste trabalho não propomos a distinção destes dois métodos de design e sim o processo de design promovendo o desenvolvimento.

Enfoque regional, conforme Schumacher (1973 pg. 157) tem a finalidade de levar ajuda aos que mais precisam dela, o que não acontece no Brasil, pois o desenvolvimento ocorre em regiões muito desenvolvidas ocasionando dois males geminados do desemprego em massa e da migração em massa para áreas metropolitanas. Cada região ou município do país necessita ter seu próprio desenvolvimento.

De acordo com Schumacher (1973, pg. 150) "se forem introduzidas novas atividades econômicas que dependam de educação especial, organização especial e disciplina especial, de um padrão que não é inerente à sociedade recebedora, a atividade não promoverá um desenvolvimento salutar e é muito mais provável que o dificulte. Ficará como um corpo estranho que não pode ser integrado e agravara ainda mais os problemas da economia".

Para que um designer de produtos possa colaborar efetivamente no desenvolvimento de produtos sustentáveis devemos aprofundar um pouco mais o campo de atuação. Segundo Manzini (2005) o termo design industrial deve ser entendido no seu significado mais atual, que não se aplica somente a um produto físico (definido por material, forma e função), mas que se estende ao sistema-produto. Isto é, ao conjunto integrado de produto, serviço e comunicação.

Esta extensão do design industrial gerou uma conscientização acerca do problema ambiental e reorientou o comportamento social, isto é, da procura por produtos e serviços que motivem a existência de tais processos.

O impacto provocado no ambiente pelas atividades humanas depende de três variáveis fundamentais:

- A população,

- A procura do bem-estar humano e a

- Eco eficiência das tecnologias aplicadas.

Tanto Schumacher (1973), como Manzini (2005) enfocam, as questões sociais, regionais e as tecnologias, são fundamentais no processo de inserção do design nestas culturas.

De acordo com Barizon (2004), as atividades econômicas têm suas raízes na comunidade, a ela prestam contas e nela se distribuem os frutos da produção. Assim proporcionam condições para regenerar a comunidade, prestar serviços e tratar de seus problemas ambientais e sociais.

O design de produtos sustentáveis, incorporado na estrutura socioeconômica, poderá corroborar com o desenvolvimento destas regiões sem descaracterizá-las culturalmente e ainda poderá gerar ações sociais que promovam a restauração da dignidade humana por meio do trabalho.

\subsection{Regionalismo e Inclusão social}


Para solucionar as necessidades das populações marginais, Margolín (2003) descreve a prática laboral social onde um designer atuaria em conjunto a um grupo de trabalhadores sociais que fariam uma análise do que ocorre no sistema do usuário (pessoa, família, grupo, organização ou comunidade) e os aspectos dentro do ambiente com o qual o sistema do usuário interage.

Na visão de Margolín, seria exatamente no aspecto físico/espacial onde um designer atuante do "modelo social de design" deveria intervir:

\begin{abstract}
O aspecto físico/espacial, (...) abarca todas as coisas criadas pelos seres humanos tais como objetos, edifícios, ruas, e sistemas do transporte. Os arredores físicos inadequados e os produtos inferiores podem afetar a segurança, a oportunidade social, o nível da tensão, o sentido de pertencer, a autoestima, ou ainda a saúde física de uma pessoa ou de várias pessoas numa comunidade. Um ajuste pobre, com um ou mais aspectos dominantes pode estar na raiz do problema do sistema do usuário, criando assim uma necessidade humana (Margolín, 2003, 2).
\end{abstract}

Por outro lado, Papanek (1977) em seu livro Design for the real world, traça as diferenças entre designers sociais responsáveis e os que desenvolvem seu trabalho num mercado comercial.

Papanek enfatiza que os designers sociais responsáveis devem organizar suas próprias intervenções fora do mercado de consumo, mas o autor não esclarece como isto poderia ser feito.

Margolín defende que profissionais sociais e designers que desejam desenvolver o trabalho social responsável, poderiam encontrar maneiras de trabalharem juntos. $\mathrm{O}$ autor acredita que os designers encontrarão muito mais aliados nas profissões relacionadas com a saúde, a educação, o trabalho social, o envelhecimento, e a prevenção do crime do que se pode evidenciar na análise de Papanek.

Margolín propõe outra alternativa como método de pesquisa para detectar onde e como um designer poderia intervir responsavelmente: o método da observação participante.

Isto exigiria aos designers que incorporassem alguns aportes metodológicos das ciências sociais, com o objetivo de observar e documentar as necessidades sociais que podem ser satisfeitas com intervenções do design.

Por este motivo, os defensores do processo de inclusão social trabalham para mudar a sociedade, a estrutura dos seus sistemas sociais comuns e atitudes em todos os aspectos: educação, trabalho, saúde, lazer, etc. Sobretudo, a inclusão social é uma questão de políticas públicas, pois cada política pública foi formulada e basicamente executada por decretos e leis, assim como em declarações e recomendações de âmbito internacional (como o Tratado de Madrid).

Quando isto acontece, podemos falar em educação inclusiva, no lazer inclusivo, no transporte inclusivo e assim por diante. Uma outra forma de referência consiste em dizermos, por exemplo, educação para todos, lazer para todos, transporte para todos. - DESIGN PARA TODOS.

\title{
3 Procedimentos e Métodos
}

O método da Observação Participante descrito por Margolin, a abordagem lançada por Papanek, na década de 70 sobre Design Social e o conceito mais atual de Design Thinking revelam um aspecto do Design que privilegia a sustentabilidade, o relacionamento entre os atores de um projeto, pensamento abdutivo e autenticidade projetual (Eler, 2010), e a percepção de que Design é uma metodologia cujo ponto central é a resolução de problemas por meio da criatividade. 
Os pontos de contato entre os três métodos estão no protagonismo do usuário, tanto na usabilidade, quanto na solução do problema proposto. A aplicação das metodologias do Design Social e do Design Thinking necessitam igualmente de equipes de projeto compostas por profissionais de diferentes expertises, entre eles: usuários, fornecedores de insumos, experts nos temas abordados, representantes do setor produtivo entre outros (stakeholders). E por ser um processo que se desenvolve em parceria com a população a ser atendida - ou seja, um processo centrado no usuário - valoriza-se o contexto onde a situação ocorre e destaca-se o conhecimento que as pessoas envolvidas têm sobre o problema em questão (cocriação).

Quadro 1: Etapas da Metodologia do Design Thinking

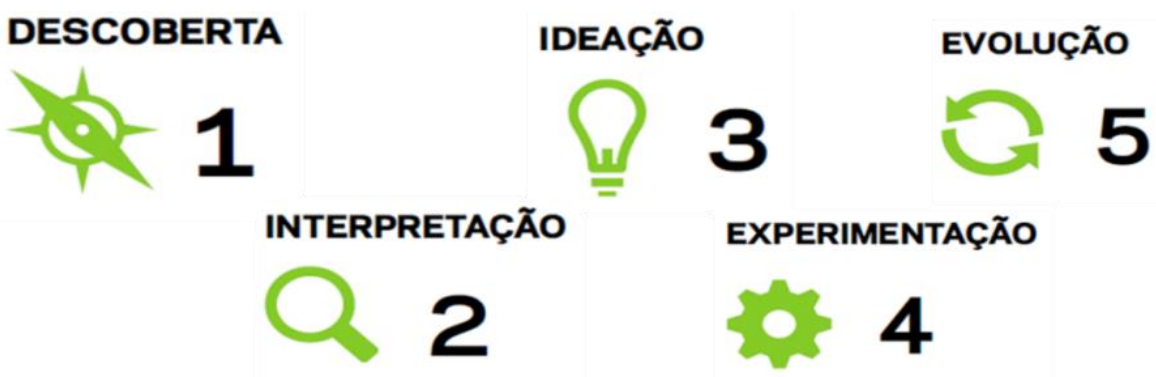

Fonte: Adaptado de STICKDORN e SCHNEIDER, 2014.

\section{Design Thinking como Método de Observação Participante}

A Associação Boa Esperança foi fundada em outubro de 1997 com objetivo de conquistar melhorias para a comunidade rural e para os agricultores. Localizada na zona rural do município de Barbalha, na Região do Cariri Cearense, a comunidade tem como principal atividade a fabricação de óleos a partir do extrativismo, que consiste na recolecção ou extração sistemática de recursos naturais. Tal fabricação é repassada de geração para geração, garantindo a continuidade dos negócios. A comunidade também trabalha com outros produtos, como sequilhos, petas e doces diversos, além do artesanato.

\subsection{Descobrir}

A primeira ação do projeto foi a visita à Sede da Associação e em reunião com os agricultores associados os alunos puderam descobrir (fase1: descobrimento) as necessidades e as possíveis demandas para o Design. Além das demandas, os alunos entrevistaram os agricultores para entenderem os processos de produção, o envase, a comercialização e o armazenamento dos produtos. Ao término da visita ficou acordado com os agricultores associados que a principal necessidade seria a criação de uma Identidade Visual que pudesse ser aplicada a qualquer produto produzido pela Associação.

A coleta do coco Babaçu e da Macaúba é realizada na chapada do Araripe - região em que a comunidade está inserida -, e a quebra dos mesmos é feita com pedras e marreta, para a retirada das amêndoas que darão origem aos óleos. Todo o processo é realizado de maneira artesanal, e todas as partes do coco são utilizadas na produção: suas cascas, por exemplo, são utilizadas para fazer o fogo que facilita a extração do óleo, vendido no comércio, ou utilizadas pelas mulheres da comunidade como material para artesanato. 

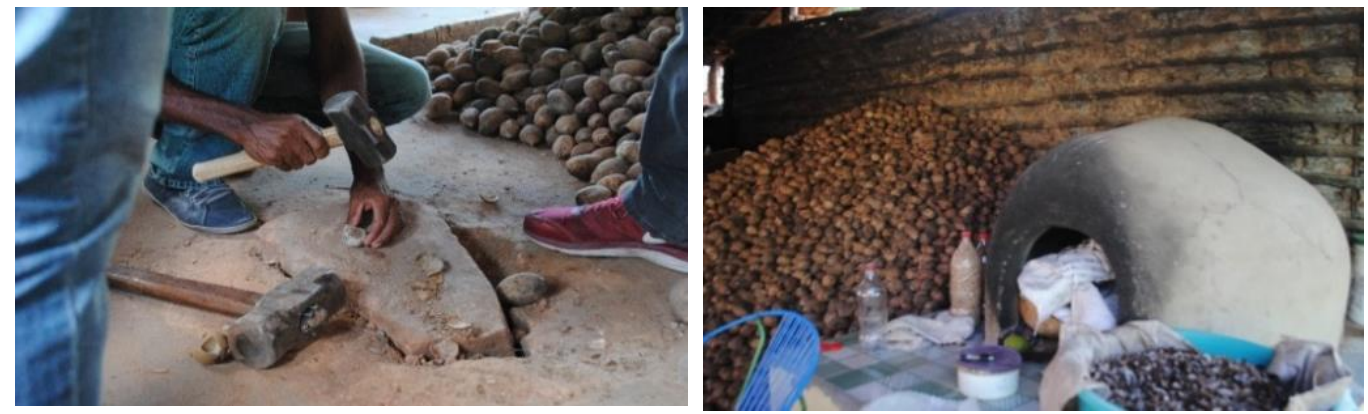

Fonte: Autor

\subsection{Interpretar}

$\mathrm{Na}$ segunda etapa do projeto os alunos deveriam interpretar (fase2: interpretação) e analisar todas as informações recebidas dos agricultores e transformar essa experiência em ícones, símbolos e sensações que pudessem expressar de forma objetiva o que representava a Associação Boa Esperança e seus associados.

A interpretação neste caso ocorreu de duas formas: a primeira, deveriam entender e representar os agricultores e a Associação, com todas as características e peculiaridades; a segunda os alunos deveriam analisar o mercado, os consumidores e os locais onde os produtos seriam comercializados. Desta forma a identidade visual da Associação estaria inserida no meio à qual ela pertence sem deixar de atender as exigências de competitividade.

\subsection{Ideação}

Ideação é a fase de geração de alternativas (fase3 ideação), a geração das alternativas iniciais foram desenvolvidas no PET Design que iniciou o projeto estudando a etnografia local e analisando as informações obtidas nas entrevistas, foram apresentadas no segundo encontro com os agricultores e de acordo com a metodologia do Design Thinking a Co-criação (participação de todos os envolvidos no processo) é fundamental e necessária, mas neste caso só ocorreu depois de apresentado as primeiras alternativas, a contribuição dos agricultores foi fundamental, eles corrigiram alguns símbolos criados pelos alunos, porque segundo eles: "este desenho aqui do coco não parece ser Macaúba". Somente após estas observações é que se chegou ao resultado final da marca. 
Foto2: Reunião com os agricultores - Co-criação da marca.
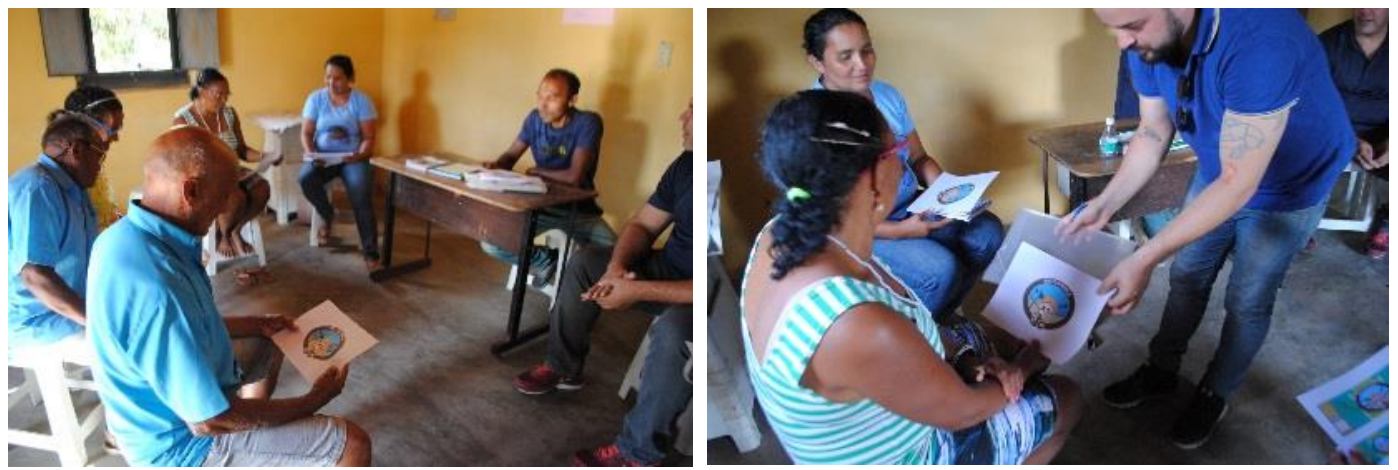

Fonte: Autor

\subsection{Experimentação}

A experimentação ou prototipagem (fase4 experimentação) assumem nessa metodologia uma forma mais livre de aplicação, ou seja, o designer pode representar suas ideias por meio de representações que não são necessariamente produtos impressos ou em modelos tridimensionais.

Na Associação optou-se por aplicar a marca a um rótulo de uma garrafa para os óleos de coco Babaçu e Macaúba, por facilitarem a visualização por parte dos agricultores e por este produto representar o maior volume de produção da Associação.

Foto3: Aplicação da marca em um rotulo - prototipagem.

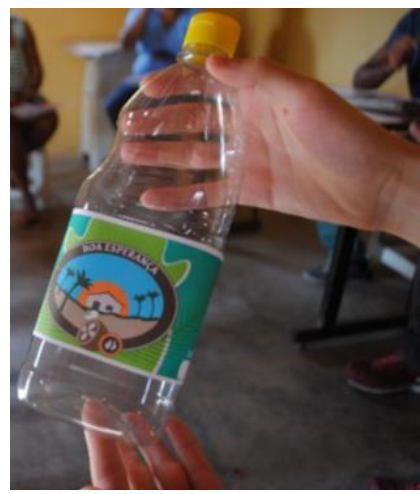

Fonte: Autor

\subsection{Evolução}

Na metodologia do Design Thinking o processo de design não termina logo após a entrega dos trabalhos, é um processo continuo, evolutivo e constante. A evolução (fase5 evolução) envolve planejar os próximos passos, comunicar as ideias e implementar.

Como resultado desse projeto interdisciplinar, integrador a Identidade Visual da Associação Boa Esperança foi aprovada pelos agricultores associados e está em fase de implementação. Ficou 
definido também que os próximos passos serão a criação de todo o material gráfico para a Associação, além da criação de uma barraca de feira apropriada para a exposição dos produtos.

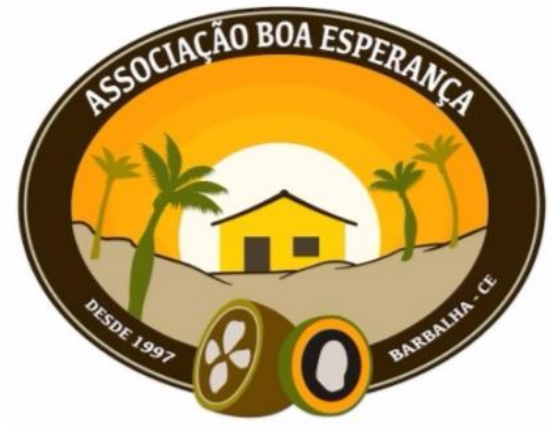

Fonte: Autor

\section{Considerações Finais}

O design no Brasil passa por um momento muito importante, há um crescimento quantitativo de instituições de ensino, o governo tem criado órgãos de incentivo e fomento da profissão, o mercado tem reconhecido o valor e a importância do design, enfim o momento é único e decisivo, decisivo, pois o design pode tomar rumos que orientem a profissão no cumprimento do seu papel na sociedade. A parceria firmada entre o PET Design, o Instituto Agropólos e a Enactus proporcionou aos alunos do Curso de Design de Produtos da UFCA uma experiência única demonstrando que as metodologias do Design possibilitam a Inclusão Social por meio da integração da população e o desenvolvimento de produtos sustentáveis.

Pudemos perceber que o Design Thinking muito além de um propósito ou metodologia de projeto vem ganhando notoriedade no mundo pois além de ter uma aplicação ampla, a preocupação com usuário e a forma de resolução dos problemas tem destacado os resultados obtidos pelo design na sociedade. Essas preocupações vão aos poucos penetrando a trama do ensino e tomando a consciência do estudante, ampliando a discussão das questões que envolvem o usuário e dessa forma alterando a formação em Design nas universidades brasileiras.

O objetivo deste projeto foi desenvolver uma identidade visual à comunidade, para melhorar os produtos e consequentemente o aumento das vendas, os resultados ainda não foram mensurados do aspecto econômico, pois o processo ainda está em implantação, mas, do ponto de vista educacional o projeto superou as expectativas tanto dos alunos, quanto dos professores envolvidos.

O Design Thinking como método de inclusão social e as teorias de Papanek e Margolin compreendem o ser humano de forma integral, envolve valores; e a melhoria de vida não se traduz apenas com o incremento da renda, mas também por meio da incorporação de valores socioambientais que promovam o desenvolvimento sustentável das comunidades que participaram deste projeto. Nesse aspecto o projeto também superou as expectativas, a Associação Boa Esperança e o Instituto Agropolos ampliaram a parceria e o projeto será estendido a outras nove associações no interior do Estado do Ceará. 
As metodologias utilizadas nesse projeto são conhecidas e bem exploradas por diversas áreas do design, mas aplicação como projeto de inclusão social em comunidades de extrema pobreza no interior do Estado do Ceará demonstra que o design pode fazer algo pelo país. Serão necessários novos estudos e discussões mais amplas, particularmente no que diz respeito à educação em Design (o que está sendo ensinado? e como estamos ensinando?) para que o gap entre academia e o mercado diminua ou não exista mais.

\section{Referências}

BENNET, Audrey. Design Studies. Theory and Research in Graphic Design. Nova York: Princeton Architectural Press, 2006.

BONSIEPE, G. Design, do material ao digital. Florianópolis, SC. FIESC, IEL, 1997.

BARIZON, S. A Responsabilidade do Design Social. Disponível na internet: www.designbrasil.org.br/opinião. Acesso em 15 fevereiro de 2016.

CONCORRÊNCIA favorece campo de design no Brasil. Folha de São Paulo [on-line].Educação. São Paulo, 82 mai 2003.20 Disponível em <http://www1.folha.uol.com.br/folha/educacao/ult305u12820.shtml>. Acesso em fev 2018.

FINDELI, Alain. Rethinking Design education for the 21st century. Em: Design issues, volume 17, number 1, winter 2001.

FRASCARA, Jorge. Diseño gráfico para la gente. Buenos Aires: Infinito, 1997.

MANZINI, E.; VEZZOLI, C; O desenvolvimento de produtos sustentáveis. São Paulo: Edusp, 2005.

MARGOLIN, V. "Um modelo Social de Design: Questões Práticas e Pesquisa". Revista Design em Foco, vol.I, Ano 1, Universidade do Estado da Bahia, Salvador, 2003.

MARTINS, R. F. F. “A Gestão de Design como uma Estratégia Organizacional”. Londrina: EDUEL, 2008.

OLIVA, P. As Regionalidades do Design. ADG Brasil - Associação dos Designers Gráficos [on-line]. São Paulo: ADG, 2003, dezembro de 2003. Disponível em: <http://www.adg.org.br/Index.asp?Fuseaction=Home\&ld_Secao=5>. Acesso em: dez 2003.

PAPANEK, V. Diseñar para el mundo real: Ecología humana y cambio social. Madrid: H. Blume, 1977 SCHUMACHER, E. F. O Negócio é Ser Pequeno. Rio de Janeiro, Zahar, 1981.

SIMÕES, K. O valor do Brasil - Artigo genuíno. PEGN [on-line]. Globo. Edição 167 - dez/02. Disponível em <http://pegn.globo.com/revista/index.asp?d=/mensal/_materias/ncapa.html> Acesso em: nov 2016.

SOUZA, R. Projeto Cara Brasileira. Londrina, em nov. 2002.

WHITELEY, Nigel. Design for Society, Reaktion Books, 1994. 